\title{
Science Education of the New Millennium: Mentorship Arts for Creative Lives
}

\author{
Akbar Nikkhah \\ Department of Animal Sciences, University of Zanjan, Zanjan, Iran. \\ Email: nikkhah@znu.ac.ir \\ Received July 20 $0^{\text {th }}$, 2011; revised August 24 $4^{\text {th }}$, 2011; accepted September $1^{\text {st }}, 2011$.
}

\begin{abstract}
Science as an ultimate essence encircles theoretical and applied findings and discoveries that can only contribute to forming a trivial core. The most crucial are, however, insightful moral surroundings. The upper tree of science glorified with blooming branches of knowledge is predicted to undergo progressive declines in the strength of its education foundations unless the lower tree receives most-deserving mentorship contemplations. Mentoring rather than teaching of science will be a frontier for quality creative lives. Postmodern Mentors will create and designate definitive shapes from discoveries and findings to grant human life with ongoing peace and ultimate satisfaction. Mentors are expected to welcome and manage challenges from mentees. Challenges play crucial roles in granting mentees with creative pathways of scientific development. Science education policies are to pursue arts as a model to reach and maintain harmony. Finest harmonies are accomplished by assimilating a multitude of creative sciences as is rousing a piece of music by composing manifold melodies. Human brain communicates with arts in ways that determine various future choices of life. Artistic science education requires creative educators who can perceive, perform and analyze arts. Governments are increasingly responsible for making new policies that will allow creative public education and refined education programs. Governments should foster creative education policies at governors, educators, and learners levels. In the post-modern time, mentors and trainers themselves require frequent timely education to remain most up-to-date and creatively functional. Constant education of educators faces more practical challenges than education of learners. Effectual education of governments and policy makers on "science education policies" will be a turning point in enabling continual improvements in global science and creative life qualities. Sciences educated artistically will make and shape most yielding policies in creative science education of the new resourceful millennium.
\end{abstract}

Keywords: Science, Education, Mentorship, Arts, Creative Life, New Millennium

\section{Introduction}

The significance of creative science education to optimizing human life is increasing as science expands (Alberts, 2009a, 2009b; Nikkhah, 2011a, 2011b, 2011c). Postmodern life quality depends on the creative science education quality greater than can be imagined mainly because the demand for all to be more similarly educated increases with time (Nikkhah, 2011b, 2011c). These high-light the most fundamental roles of "education" in enabling optimum human uses of nature. Humans are exposed to a variety of environments whose utilization efficiency is orchestrated and obliged by creative education systems qualities. As such, policy-making in creative science education is key to timely human developments. More important than feeding the rising world population is their adequate quality creative education. Feeding guts will only be a preliminary concern in the crucial face of nourishing creative brains and social intelligence in the new millennium. Effective policy-making in science education for any society relies on its legislators' and scientists' visions and prospectus insights. In support of the incremental importance of adequate investments in creative science education (Nikkhah, 2011c), for instance, Steven Weinberg, the 1979 physics nobelist, recently urged to help shift away the economy balance from private consumer goods to education and scientific research (Weinberg, 2011). Special care must be dedicated to both pure and applied sciences. One without the other will not make a long-term sense in optimizing life qualities. Advancements in pure sciences will fuel expansion of applied sciences that will allow progressive development of new integrative theories. The circular dependence will maintain sufficient dynamics in creative science education for consistent improvements in life quality.

Science has embodied inexpressible progress especially since the agricultural revolution. A following wave of science glorification has occurred in the 19th and 20th centuries involving the birth and growth of modern physics and quantum mechanics. These accomplishments have totally transformed human life and enabled more efficient utilization of natural resources and time. However, such advancements in tangible science and technologies have often remained uncoupled from applications and implications that should reflect in adequately satisfied and moral quality lives worldwide. Therefore, the primary objective is to address and describe postmodern creative science and life quality interrelationships. An additional objective is to propose global programs that will help in timely achievements of optimal real-life science goals. Moreover, dynamic and artistic policy-making in creative science education of the new millennium will be described. Creative science education will be delineated in an "arts" context to emphasize artistic sciences to be the postmodern scientific arts. Frontiers in the global science of creative science education will be discussed. It will be reasoned how creative science education can only be an art to remain advantageous to the betterment of postmodern creative lives.

\section{Creative Science of Science Education: An Evolving Global Supremacy}

With the world population mounting above 9 billion by 2050, 
“creative education” becomes an increasingly important entity in human life. Major concerns are not limited to how efficiently conduct animal agriculture to safely and securely feed the rising populations. A key concern is how effectively to educate such populations to be able to most efficiently utilize science and technology driven natural and synthetic resources. Creative education is not limited to original young learners and students. The governors, administrators and educators require constant and continual education more than before and more practical than others. In a nut shell, it is only with most applied education of concepts to policy-makers and governors that science and technology can persist to significantly improve life worldwide. The importance of "creative science education" and "mentorship arts" have recently been subjects of global importance for timely improvements in life quality (Alberts, 2009; Nikkhah, 2011a).

\section{Mentorship Principles and Challenges}

It is compelling to consider "education" as a most realistic reason for humans to find meanings in life. The continuing emphasis on creative science education supports the consideration (Alberts, 2008, 2009a, 2009b, 2009c). Summing up centuries of contemplation in science and most crucially its education, knowledge must synthetically be transformed into insights to advance progressively. This transformation enhances in influence as knowledge grows deeper. For this transformation to occur persistently, creative education must focus on sufficiently simple but sophisticated inter-group discussions from the very beginning in elementary schools. There has always been a belief that more junior students are too young for certain life lessens received by the more senior peers. Such erroneous practices considerably delay students' consciousness in grasping their powerful thought nature and benefiting the community in multiple aspects. Science educators must gain distinction in persuading professional confrontational and provoking opinion and view exchange among students and trainees. Prevailing silence on students' part and one-way teaching should be discouraged and minimized. Such approaches will allow mentees to envision much earlier what educators or mentors have realized later in life, thus offering mentees enormous potential to visualize beyond mentors' images.

By science definition, mentors are to replace pure instructors, and to vastly welcome and manage challenges from mentees. Challenges play crucial roles in introducing mentees with integrated pathways of creative scientific development. The resulting pictures will be eagerly prone to future revisions and elaborations as mentees themselves step into such pathways. This systematic and circular education will strengthen science roots in mentees' minds and will uphold a sturdy body for creative science.

\section{Global Creative Education Models}

The proposed feature simply resembles a tree with its roots, base, major and minor branches, leaves, and fruits the foremost. That is a global perception for creative science without which all other theoretical and experimental accomplishments will not gain lasting power and productivity. The upper tree of science glorified with blooming branches of knowledge is predicted to undergo progressive declines in the strength of its education foundations unless the lower tree receives most-deserving mentorship contemplations. What humans have achieved and built thus far, and particularly over the last 4 centuries, now we begin to realize that concern mostly the upper tree. With uncovering and discovering more quantitative and qualitative science, the lower tree must be fortified for more blooming and productive upcoming generations. The lower tree is essentially concerned with moral commitments to training more creative upcoming mentors/scientists than those of past and present times. This is an obligation for creating an integrated shape for global science that will maintain its evolving trend.

\section{Morality and Science: Simplification of an Elusive Concept}

Although known and discussed for centuries, morality is an elusive concept that has rarely, if at all, been simply defined in very few global terms. Morality should essentially be incessantly refined and interpreted, such that science can capaciously realize its prevailing role in improving man's life. With the imaginable tree of creative science growing as a circle, for instance, theoretical and applied findings and discoveries can only contribute to its core or the insignificant central point. What shape morality are the surroundings of the core or the essentialities maintaining an integrated circular shape. Without such dense environs, the circle would loose its essence and integrity, becoming a straight line. However, even with the central hub being even as infinitesimal as an invisible point, the circle will still be a circle. These concepts implement a phenomenon that creative science would be entirely meaningless without its moral elements, even if filled with expanded experimental novelties.

\section{Structuring Postmodern Science Education}

Creative education for scientists and mentors in the new millennium on must accordingly incorporate describing moral responsibilities alongside technical and imaginary skills. Influential thought authorities of the 20th century (e.g., Albert Einstein) had exemplified that how imagination outshine knowledge. Now, we tend to globally comprehend that while is knowledge always relatively uncovered, imagination is merely the beginning to furthering knowledge. Thus, to form and sustain a dense and rigid shape that progressively improves man's life, knowledge and imagination must be complemented with harmonizing approaches. Such much needed perceptions become an obligation as the growing knowledge gives rise to novel questions and challenges.

Science pictured as an integrated circle grants a prospect to envision where we are and where we must or must not end up. Maintaining a definitive shape for science in any major before and while enriching central cores with experimental novelties in minds and laboratories is crucial to improving man's fulfillment of time. It is only with such a representation that creative science can continue to impress upon us constructively enough to deserve investing and dedicating time, finance, and brain work.

\section{Science and Arts}

The significance of creative science education to optimizing human life is increasing as science expands (Alberts, 2009a, 2009b; Nikkhah, 2011a, 2011b, 2011c). Postmodern life quality depends on creative science education qualities greater than can 
be imagined mainly because the demand for all to be more similarly educated increases with time (Nikkhah, 2011b, 2011c). These highlight the most fundamental roles of "creative education" in enabling optimum human uses of nature. Humans are exposed to a variety of environments whose utilization efficiency is orchestrated and obliged by education systems qualities. As such, policy-making in creative science education is key to timely human developments. Science education will be increasingly regarded as a global art.

The arts are a vast subdivision of culture, made of numerous creative endeavors and disciplines. The "arts" is a more-inclusive expression than "art", which usually refers to visual arts. The arts encompass visual arts, literary arts, and the performing arts including music, theatre, dance and film, among others. By global definition, the "arts" is described as imaginative, creative, and non-science senses and data that may be studied academically. Art is born when an artist creates a stunning and inspiring object, sense, science, or experience that is considered to have artistic merits for humans. The "art" is suggested as the process that creates an artwork. The artwork or the piece of art is analyzed and scored by experts or is most practically appreciated, assimilated, and enjoyed by spectators, viewers and listeners. Art is a global activity that hosts several disciplines, including Fine Arts, Liberal Arts, Visual Arts, Decorative Arts, Applied Arts, Design, Crafts, Performing Arts, and others. Arts are the means that humans utilize to communicate with their surrounding nature and environment more insightfully. This suggests that pursuing arts makes all life affairs more efficient, more understandable, and thus more pleasurable. Therefore, an ultimate pathway to facilitate and improve "creative science education" is through contemplating arts and their assimilation with science.

\section{Science and Arts Integrations into Creative Public Education}

It is increasingly suggested that human brain systems (e.g., rbitofrontal cortex and the nucleus accumbens) communicate with arts in ways that can determine various future choices of life (Berns et al., 2009; Berns \& Moore, 2011). Artistic science education requires educators who can perceive, perform and analyze arts. Arts are performed with sophisticated delicacies and harmonies. Artists ought to acquire such skills to impress upon others while performing. That requires artists to live with their arts as they creatively practice and perform. Arts are thus become part of artists' brain organization without which all life affairs would be curtailed and imperfect. This vision suggests that human brain is kinetically always deficient unless complemented by arts. Scientists are considered analytical humans who expectedly contemplate more than many. Thus, scientists' brains are prone to greater degrees of disorganization. Accordingly, arts come to play more important roles in organizing scientists' minds. Art is highly integrated with science as is art training with science education. Creative science education must be inspired by professional arts training. Interactions among arts and science mentors will be highly encouraged. Arts performers are often seen to have proficiency in more than one field. Formatted with arts, human learning capacity increases. Should science be practiced as an art, science mentors will more efficiently direct mentees towards a variety of science fields. Without artistic mentoring, mentees will encounter numerous difficulties in learning a given science. With artistic mentorship, a multitude of sciences may be pursued enthusias- tically.

Arts and science become increasingly interrelated as science expands. Pursuing one without another is virtually impossible. Arts are prime while science is constantly incomplete. Science depends on arts far greater than arts on science, suggesting that arts are ahead of and lead science. The state-of-arts science education is hence led by arts. Music is a paramount and rational art example. Orchestrating a harmonious piece of music is comparable to mentoring creative science education. Finest harmonies could be secured by educating a multitude of sciences as is rousing a piece of music by composing manifold melodies. Sciences educated artistically will generate mentors that are cognizant of arts roles in the quality new millennium's science education.

Ease and pleasure in mentoring science is granted with multiple-science training. Basic sciences of mainly physics and chemistry conceptually fit into applied sciences such as nutriation, medicine, and engineering. Advocating sciences apart in "creative science education" will not be a goal. True and capable artists (e.g., musicians) often secure proficiency in additional arts besides their own principal art. Science will yet to learn much from arts. Science transformation into arts can optimize science education. Science education policies should pursue arts as a model to reach and maintain harmony. A first step is to develop and provide supplementary courses in arts for science mentees and mentors. Such courses will be mandatory and prepare mentees' minds for more orchestrated science training. This is similar to a music orchestra when a back-ground piece is played to shift the audience's mind into the psychological atmosphere within which mind, psych and body will experience relaxation. Accordingly, before mentors can most effectively communicate science with mentess, a mind bridge between them should be developed through which thoughts will be exchanged more passionately and productively. Arts will help to build sturdy and long-lasting mind bridges in creative science education. Arts such as music, painting, choreography, theatre, sculpture, poetry, architecture, photography, and comics among others will help to more transparently connect mentors to mentees. The connection will highly facilitate science education and insight formation. Science creates knowledge and knowledge fuels insights to further science. These are interconnected with arts.

\section{Policy-Making Obligations of Science Education}

Effective government education has received negligible global science and research attention. As a matter of science fact, insufficient education across governmental and administrative levels contributes greatly to deficiencies in most deserving and visionary time and financial investments in science and technology creation, education and their public utilization. Assigning science advisors within governments and administrations is only a single minor factor, and thus, is highly inadequate in creating an efficient global science structure. Governors and administrators are to receive most applied education on theories of science methodological impacts on life betterment. Specialized educators are to frequently update governors and policy-makers with most recent fundamental science discoveries. The main aim of such governmental education is not only to advance governors' knowledge of world science but is more pragmatically to highlight the significance of granting most deserving thought and applied credits to "creative science education”. Governors and administrators may each be expert 
in a given science field, but the key is to unite them into a unified global structure that is increasingly appreciative of a life princi- ple. The principle that governments are as important as scien- tists (if not more important) in making and refining science policies that optimally contribute to continual improvements in life quality.

\section{Science Educators Education}

Science education resembles a circle that requires revisiting all its directions to be sustained fruitfully. Such a dynamic nature will enable science education to find multiple ways out towards its accomplishments. It is often observed that science educators are not directed into continual educational programs. Systematic education does not end once one becomes an educator. The ongoing education of educators does not aim to merely keep them up-to-date in science or to motivate networking for improved science dissemination. A key goal is to revisit and refresh education principles and highlight the necessity of developing circular education with a delicate nature. One will be as much delicate in educating learners as being progresssively educated by others. Governments are increasingly becoming responsible in fostering "educator education". Thus, maintaining creative education delicacies requires periodical education of the principal educators.

\section{Societal Interrelations of Science Education}

A visionary triangular structure for dynamic science education will sustain a constantly-improving nature for science-life interactions. This structure involves 1 ) governors and administrators, 2) principal educators, and 3) learners. The governors include ministers and all related officials and administrative professionals. The educators include science and technology mentors and trainers in schools, colleges, universities, Industries, and private and semi-private institutes. The learners, by definition, are those enrolled in different academic and nonacademic institutions to obtain degrees, expertise and excellence in global fields of science and technology. With inadequate resources and time investment in each of these angles, especially the top government angle, tremendous practical shortcomings in linking science to human life will occur. Fundamental governmental education and insight dissemination are an obligation for governments and related sectors to become profoundly aware and updated of such a unified structure. The interrelationship is to be fostered in various governmental levels in a global manner. The unavoidable interconnection will be incorporated into mandatory course materials in schools, universities and industrial institutes. Emphasis will be made that creative science education requires governors and administrators to network closely and frequently with science educators and policy-makers. Governors will be quantitatively educated on estimates of science links to quality human life. These will ease designing and specifying most deserving budgets for science and non-science administrations. With such a configuretion, any learner will be a more insightful element either as educator, administrator, or governor. Consequently, policymaking in science will be productive in overcoming challenges more timely and harmonically.

\section{Science Roles in Postmodern Life Betterment}

Science and its progress should ultimately and significantly contribute to easing life affairs and creating adequate satisfaction for all humans (Nikkhah, 2011a). These are beyond improving life energy efficiency. More intense daily activities and busier schedules are not undesirable if pursued within programs that result in such moral life accomplishments. Greater activity for greater success in social and financial states should not interfere with personal and communal capacities to create atmospheres that provide all with peace of mind and physics. Under such considerations, more active daily life will despite having greater workload for body matter will cause more relaxed minds and psyches. It is not a main aim of this paper to discuss how different sports, especially mind exercise procedures, help to improve body and mind health. Instead, it is delineated how more effective and transformed perspectives into global science can entirely improve conceptual expectations from science on life quality. Science in different fields generates findings, discoveries and perspectives that enhance man's understanding of life mechanisms (Alberts, 2009). In addition, science in general and regardless of fields should yield pathways that allow humans to most efficiently utilize such new findings and discoveries. These pathways have received virtually no or little attention in global science and technology. Without optimal pathways to carry the discoveries through, science will contribute negligible to human life quality no matter how advanced technologies are resulted and accessible. The essentiality of having such science visions increases with time and as findings and innovations escalate. As such, in a more modernized environment human life will be more prone to possible disadvantages of a mismanaged and misperceived science. These highlight the significance of educating upcoming generations a science that is beyond classes, laboratories, and libraries.

Science is a discernible delineation of knowns among unknowns. Science is not an obscure territory of knowledge. It is the entirety of such delineations that should be educated. Knowledge and insight will advance, but the optimal harmony of science, no matter how much exposed or sophisticated, will persist. Science has mostly been perceived as an unlimited field of advancement without creating frontier directions and goals. Such an ambiguity will cause science and the world to encounter progressive life dissatisfaction. Definitive paths are proposed that will bestow science sufficiently empowered authorities to optimize economics and global human relations.

\section{Frontiers in Global Science Education}

Science in the postmodern era will no longer be judged based on applied and theoretical research accomplishments. The ability and capacity to retain an evolving trend in science will depend on the creation of scientists who are capable of creating more qualified and more creative than own. Those whose quality does not lie in only distinguished teaching and research. Those whose qualifications are encompassed with a distinction in development and education of pathways in which science is mentored rather than taught. Mentorship is an indefinite art while teaching is a defined job. Teaching is passing knowledge on to others while mentoring is fostering insights exchange. Teaching educates learning while mentorship develops skills to educate others. Teaching gives rise to students who graduate while mentorship creates mentees who remain students so long as they live. Teaching demands returning teachers materials taught while mentoring lead mentees to establish new concepts. Teaching is mostly a one-way communication while mentor- 
ship is an environment for thought exchanges. Teaching does not bear questioning teachers while mentoring welcomes challenges from mentees. Challenges are where mentees practice and perceive true education. Teaching is concerned with routine fixed hours while mentoring is a life-time contemplation. Teachers are employed by science while mentors employ science. Teaching motivates learning while mentoring generates mentors who can sustain an ever-improving pathway. Teachers teach science while mentors generate those who can produce science. Teaching is a task while mentorship is a commitment. Teaching's most significant outcomes are research findings and discoveries while mentoring's most important products are mentors who produce scientists capable of discovering. Teaching furthers knowledge while mentoring discovers and prepares scientists who can educate others to create insights. Knowledge is an endpoint while insight is a beginning to innovate and create more knowledge. Teaching raises science while mentoring creates pathways to advance science. Teaching is a straight line while mentoring is definitively shaped to form - for instancea circle that consists of a central point (i.e., findings and discoveries) and the surroundings (i.e., science morality). Teaching merely adds to the literature while mentoring integrates knowledge into quality life strategies. As such, teaching complicates science while mentoring simplifies life. Responsible mentoring rather than teaching of science will be a frontier for quality postmodern lives. Postmodern mentors will be cognizant of the science entirety, and will create and designate definitive shapes from discoveries and findings. These shapes will grant human life with ongoing peace and ultimate satisfaction.

\section{Conclusions and Implications}

Postmodern science will not be judged merely based on applied and theoretical research findings. The ability and capacity to retain an evolving trend in science accomplishments will depend on the creation of creative scientists who are capable of creating more qualified than own. Creative mentoring rather than teaching of science will be a leading edge for quality postmodern lives. Constant education of educators faces more challenges than education of learners. It is only with an integrated structure of governors, policy-makers and scientists that science will create and empower deserving public education. Effectual governmental education of "science education delicacies" will be a turning point in making progressive improvement in creative life quality worldwide. Education is a science in ways that science is an art. Arts are the means whereby humans communicate with the nature and the environment. Pur- suing arts will make life affairs more efficient, more understandable, and thus more pleasurable. Arts will help to build inspiring irreplaceable links between mentees and mentors. Thus, creative public science education should be performed as arts to contribute to ongoing quality life betterment. Science does possess a rigid form, with theoretical and applied findings and discoveries only contributing to forming its trivial core. Crucially, the most vital elements are insightful moral surroundings. Making the most fruitful education policies necessitates conceptual appreciation of the moral constituents of science mainly concerned with mentorship commitments. Sciences educated artistically will enable making and shaping most yielding policies in the creative science education of the new resourceful millennium.

\section{Acknowledgements}

The author is grateful to nature and environment for inspiring thoughts of programming and optimizing science education policies in the third millennium.

\section{References}

Alberts, B. (2008). Considering science education. Science, 319, 1589. doi:10.1126/science.1157518

Alberts, B. (2009a). Making a science of education. Science, 323, 15. doi:10.1126/science.1169941

Alberts, B. (2009b). Redefining science education. Science, 323, 437. doi:10.1126/science.1170933

Alberts, B. (2009c). Science for science. Science, 324, 13. doi:10.1126/science.1174131

Berns, G. S., \& Moore, S. E. (2011). A neural predictor of cultural popularity. Journal of Consumer Psychology, In Press. http://www.sciencedirect.com/science/article/pii/S1057740811000532

Berns, G. S., Capra, C. M., Moore, S., \& Noussair, C. (2010). Neural mechanisms of the influence of popularity on adolescent ratings of music. Neuroimage, 49, 2687-2696.

Collins English Dictionary. Entry on the free dictionary. http://www.thefreedictionary.com/arts

Nikkhah, A. (2011a). Structuring science education in the new millennium: Authorizing a succeeding integrity. In progress in education. NY: Nova Publishers Inc.

Nikkhah, A. (2011b). Science for quality life. In progress in education. NY: Nova Publishers Inc.

Nikkhah, A. (2011c). Postmodern governments and science education. Journal of Public Administration and Governance, 1, 71-74.

Weinberg, S. (2011). Nobelist Steven Weinberg calls for bigger science, more taxes. ScienceNOW.

http://news.sciencemag.org/sciencenow/2011/06/nobelist-steven-wei nberg-calls-f.html?etoc 